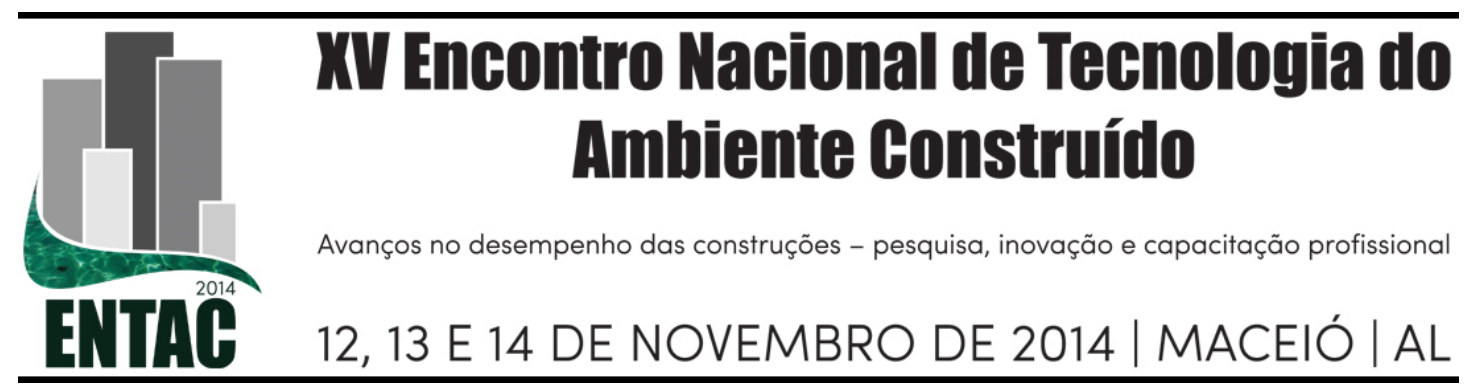

\title{
ARGAMASSAS COM SUBSTITUIÇÃO PARCIAL DO AGREGADO MIÚDO POR PÓ DE MÁRMORE
}

\section{SALES, Angela Teresa Costa (1); SÁ, Bárbara Ramos Carvalho de (2); SANTOS, Débora de Góis (3)}

(1) Universidade Federal de Sergipe, telefone (79) 2105-6700, e-mail: angelasales19@gmail.com (2) RGM Construções Ltda, e-mail: barbara_rcarvalho@hotmail.com (3) Universidade Federal de Sergipe, email: deboragois@yahoo.com.br

\begin{abstract}
RESUMO
Resíduos das indústrias de pedras ornamentais podem tornar-se um grave problema ambiental, pelo grande volume gerado e frequente disposição inadequada. A construção civil está entre os maiores consumidores de recursos naturais não renováveis. A extração de agregados, das margens e leitos dos rios ou depósitos naturais, modificam a paisagem e a biodiversidade. Esse estudo buscou analisar a viabilidade da substituição parcial do agregado natural pelo pó de mármore, em argamassas para assentamento e revestimento de alvenarias. Produziram-se seis misturas, com teores de substituição de 0\%, 20\% e 40\%, em argamassas com dois traços diferentes, de 1:1:6 e de 1:2:9, em volume, fixando-se a relação entre aglomerantes e agregados. Relações água/aglomerantes foram obtidas através de ensaios de espalhamento, num intervalo de $250 \pm 20 \mathrm{~mm}$. Foram realizados ensaios de medida porosidade e ensaios mecânicos de resistência à compressão axial e de tração indireta. Resultados mostraram que, ao substituir $20 \%$ do agregado pelo pó, houve redução da absorção e do índice de vazios. Porém, elevando-se esse teor para 40\%, houve aumento da porosidade da argamassa endurecida. Testes mecânicos mostraram, nos dois traços, variações semelhantes da resistência à compressão, à tração indireta e no módulo de elasticidade. Para traço 1:1:6, substituindo-se 20\% do agregado pelo pó, a resistência à compressão aumentou em $10 \%$, comparando-se à argamassa sem substituição. Substituindo-se 40\%, a resistência à compressão reduziu-se em 30\%. Para o traço 1:2:9, houve redução da resistência à compressão, com o aumento do teor de substituição. O módulo da elasticidade foi maior para o traço 1:1:6, com $20 \%$ de substituição. Sob tração indireta, substituindo 20\% do agregado, houve aumento de 28,57\%, para o traço 1:1:6. Substituindo 40\%, houve redução de 32,47\%. Para o traço 1:2:9, maiores teores de substituição levaram a menores resistências à tração indireta.
\end{abstract}

.Palavras-chave: pó de mármore, argamassa, porosidade, desempenho mecânico.

\begin{abstract}
Wastes of ornamental stones production are considered a serious environmental problem due to high generation and improper disposal. Construction industry is considered as a great non-renewable resources consumer. High consumption of aggregates extracted from rivers or natural deposits can degrade scenery and biodiversity. This study investigated the feasibility of partial replacement of fine aggregate by marble powder in mortar. Six mixtures with replacement levels of 0,20 and $40 \%$ were produced for mortars with two different proportions, 1:2:9 and 1:1:6. The water/binder ratios were obtained by flow tests in the range of $250 \pm 20 \mathrm{~mm}$. Physical tests were performed to measure water absorption, void index and specific masses, besides mechanical tests for compressive and tensile strength measuring. Results showed that by replacing $20 \%$ of fine aggregate by powder, there was reduced water absorption and void ratio. As the powder content increased to 40\%, the hardened mortar porosity increased. For different proportions, the mechanical test results have shown similar variations in the compressive, tensile indirect strength and modulus of elasticity. For mortars with proportion 1:1:6, by replacing $20 \%$ of fine aggregate by powder, the compressive strength has increased by $10 \%$ compared to
\end{abstract}


reference mortar.For replacement of $40 \%$, the compressive strength was reduced by $30 \%$. For mortars with proportions 1:2:9, there were reductions of compressive strength with increasing replacement contentt. The elastic modulus was higher for mortar with proportion 1:1:6 with 20\% replacement. Under indirect tensile tension, replacing 20\% of the aggregate resulted in increase of $28.57 \%$ for mortar with proportion 1:1:6. Replacement of $40 \%$ caused a reduction of $32.47 \%$ compared to reference mortar. For mortar with proportion 1:2:9, higher replacement level has led to lower indirect tensile strength.

.Keywords: marble powder, mortar, porosity, mechanical behavior.

\section{INTRODUÇÃO}

A questão da preservação ambiental tem envolvido vários setores da sociedade. As ameaças de esgotamento das matérias-primas e de degradação ambiental, que podem comprometer o desenvolvimento econômico, social e ambiental, têm levado à adoção de práticas de redução, reutilização e reciclagem dos resíduos. A construção civil, por ser um dos setores industriais que mais consomem matérias primas e energia em seus processos produtivos, deve empenhar-se em incorporar seus resíduos e de outras indústrias, contribuindo para o desenvolvimento sustentável e a redução dos custos.

Os agregados são os recursos minerais mais consumidos no mundo. A maior parte dos agregados miúdos naturais é extraída dos leitos dos rios, causando prejuízos ambientais, por prejudicarem a biodiversidade e o regime de vazão dos rios, levando o poder público a estabelecer restrições à exploração. Os resíduos industriais geram sérios problemas, pela falta de disposição adequada, poluindo o solo e os mananciais. Além disso, ao se descartar erradamente os resíduos, perdem-se materiais que poderiam ser reciclados ou reutilizados, gerando outros bens de produção, a exemplo da utilização de resíduos como agregados para concretos e argamassas.

O presente trabalho teve como objetivo analisar a influência da substituição do agregado miúdo por resíduos do beneficiamento do mármore, em diferentes teores, sobre propriedades físicas e mecânicas das argamassas, visando sua utilização em assentamento e revestimento de alvenaria.

Nas iniciativas de reciclagem de resíduos, devem-se analisar, criteriosamente, as vantagens e desvantagens. A maioria das pesquisas envolvendo reciclagem somente se limita a aspectos técnicos do material. Santos (2011) afirma que a viabilidade econômica é indispensável para sua eficácia, pois os benefícios sociais somente vão se consolidar se o produto resultante gerar empregos, diminuir o volume de aterros e evitar a contaminação do ambiente. A Lei Federal no 12.305/10 instituiu a Política Nacional de Resíduos Sólidos (PNRS) (BRASIL, 2010) e prevê a redução na geração de resíduos, levando em consideração hábitos sustentáveis e prevendo a reutilização e reciclagem dos resíduos sólidos. A aplicabilidade da lei, no entanto, exige que os órgãos fiscalizadores tenham uma atuação condizente, de modo a coibir práticas ambientalmente prejudiciais.

As rochas ornamentais e de revestimento são materiais naturais, extraídos na forma de blocos ou placas, cortados e beneficiados por meio de esquadrejamento, polimento e lustro. A situação brasileira, no ano de 2008 , em comparação com o mercado mundial, era de $4^{\circ}$ maior produtor $\left(8,1 \%\right.$ da produção mundial); $5^{\circ}$ maior exportador em volume físico (6,3\% do total mundial) e $2^{\circ}$ maior exportador de granitos brutos $(11,8 \%$ do total mundial). A cadeia produtiva geradora era de cerca de 11000 empresas, sendo mais de $60 \%$ referente às marmorarias (CHIODI FILHO; CHIODI, 2009). Segundo Moura et al. (2002), durante a serragem, cerca de $25 \%$ a $30 \%$ dos blocos de mármore e granito são transformados em resíduos. Gobbo et al. (2004) afirmam que esses resíduos podem ser triturados, gerando agregados com grande potencial de utilização em concretos e argamassa, substituindo areias extraídas dos rios e tornando-se uma alternativa viável 
para a construção civil. Segundo Calmon et al. (2005), no estado do Espírito Santo, produzia-se cerca de 65.000 toneladas de artefatos de rochas ornamentais por mês, levando a uma situação crítica, pela falta de áreas para a deposição dos resíduos, sendo lançados em rios, contaminando o meio ambiente.

Mármores são rochas metamórficas formadas, basicamente, por minerais carbonáticos, como calcita $\left(\mathrm{CaCO}_{3}\right)$ e dolomita $\left(\mathrm{Ca}, \mathrm{MgCO}_{3}\right)$ (COURA, 2009). No beneficiamento, os resíduos resultam em agregado miúdo, com características físicas, químicas, mecânicas e mineralógicas que viabilizam seu uso em argamassas. Adicionado à mistura, o resíduo age como um filler e, possuindo granulometria fina, diminui a porosidade da argamassa, influenciando propriedades como trabalhabilidade, permeabilidade e densidade (REIS; TRISTÃO, 2007). No estudo de Moura et al. (2002), resíduos de corte de granito e mármore substituíram 5\% e $10 \%$ da areia da argamassa. Houve aumento na resistência à compressão, embora seja sabido que, em argamassa de reparo, assentamento e revestimento, a maior resistência mecânica reduz sua capacidade de deformação e aumenta a possibilidade de fissuração. Santos (2011) substituiu totalmente a areia lavada pelo resíduo de pó de mármore, para diversos traços de argamassa. Percebeu-se redução do consumo de cimento, aumento da resistência à compressão axial e da massa específica.

\section{MATERIAIS E MÉTODOS}

Foi utilizado cimento CP II Z-32 com índice de finura de 1,70\%, medido segundo a norma NBR 11579 (ABNT, 2013a) e tempo de pega de 2h20, pela NBR NM 65 (ABNT, 2003b). Mediu-se sua massa específica real, seguindo-se a NBR NM 23 (ABNT, 2001), resultando em 3,02 $\mathrm{g} / \mathrm{cm}^{3}$. A cal do tipo $\mathrm{CH}-\mathrm{I}$ apresentou massa específica real de $3,0 \mathrm{~g} / \mathrm{cm}^{3}$. A adição inerte, obtida do resíduo do corte de mármore, foi a mesma utilizada por Porto (2013), tendo sido seca e peneirada na peneira de $0,30 \mathrm{~mm}$ de malha. As composições qualitativas das fases cristalinas e química do pó (Tabelas 1 e 2) foram obtidas por difração de raios X (DRX) e espectroscopia de energia dispersiva (EDS).

Tabela 1 - Composição do pó de mármore em termos de fases

\begin{tabular}{|l|l|}
\hline \multicolumn{1}{|c|}{ Fase } & \% massa \\
\hline Carbonato de Cálcio - Calcita $\left(\mathrm{CaCO}_{3}\right)$ & 56,2 \\
\hline Dolomita $\left(\mathrm{CCa}_{0,5} \mathrm{Mg}_{0,5} \mathrm{O}_{3}\right)$ & 38,5 \\
\hline Quartzo $\left(\mathrm{SiO}_{2}\right)$ & 5,2 \\
\hline
\end{tabular}

Fonte: Porto (2013)

Tabela 2 - Proporções dos elementos químicos do pó de mármore

\begin{tabular}{|c|c|c|}
\hline Elementos & \% em massa & Átomos (\%) \\
\hline $\mathrm{C}$ & $14,91 \pm 0,12$ & $24,36 \pm 0,29$ \\
\hline $\mathrm{Mg}$ & $7,34 \pm 0,12$ & $8,36 \pm 0,13$ \\
\hline $\mathrm{Al}$ & $0,64 \pm 0,11$ & $0,66 \pm 0,11$ \\
\hline $\mathrm{Si}$ & $11,43 \pm 0,15$ & $11,26 \pm 0,15$ \\
\hline $\mathrm{Ca}$ & $65,69 \pm 0,55$ & $45,37 \pm 0,38$ \\
\hline
\end{tabular}

Fonte: Porto (2013) 
O pó de mármore apresentou diâmetro máximo de $0,30 \mathrm{~mm}$ e módulo de finura de 0,36. Foi determinada sua finura, seguindo-se a norma NBR 9202 (ABNT, 1985), resultando em 33,6\%. A massa específica real segundo a norma NBR NM 23 (ABNT, 2001) resultou em $2,75 \mathrm{~g} / \mathrm{cm}^{3}$. Determinou-se a massa unitária do pó de mármore, seguindo-se a norma NBR NM 45 (ABNT, 2006a), resultando em $0,88 \mathrm{~g} / \mathrm{cm}^{3}$. O agregado miúdo utilizado foi areia de cava. Foram realizados ensaios de caracterização do agregado, obtendo-se massa específica real de $2,62 \mathrm{~g} / \mathrm{cm}^{3}$ (ABNT, 2009) e composição granulométrica, de acordo com a norma NBR NM 248 (ABNT, 2003), determinando-se diâmetro máximo de 1,2 mm e módulo de finura de 1,69.

Foram produzidas seis misturas de argamassa de cimento, cal e areia, com substituição parcial da areia por pó de mármore, em teores de $0 \%, 20 \%$ e 40\%, para serem usadas, tanto em revestimento, quanto em assentamento de componentes de alvenaria. Estabeleceram-se os traços em volume, de 1:1:6 e 1:2:9 (cimento:cal:agregado miúdo), mantendo-se o traço genérico de 1:3 (aglomerante:agregado), em composições que são usuais para aplicação nesses serviços. Na Tabela 3, está mostrada a nomenclatura das misturas com suas respectivas composições. As relações água/aglomerantes foram obtidas, fixando-se o espalhamento, medido segundo a norma NBR 13276 (ABNT, 2005), num intervalo de $250 \pm 20 \mathrm{~mm}$.

Tabela 3 - Nomenclatura e composição das argamassas

\begin{tabular}{|c|c|c|}
\hline Argamassas & Traço em volume & Teor de pó de mármore (\%) \\
\hline \multirow{2}{*}{ A6P00 } & \multirow{2}{*}{$1: 1: 6$} & 0 \\
\cline { 1 - 1 } A6P20 & & 20 \\
\cline { 1 - 1 } A6P40 & \multirow{3}{*}{$1: 2: 9$} & 40 \\
\cline { 1 - 1 } A9P00 & & 0 \\
\hline A9P20 & & 20 \\
\hline A9P40 & & 40 \\
\hline
\end{tabular}

Moldaram-se os corpos de prova de acordo com a norma NBR 7215 (ABNT, 1997). Após 24 horas, os corpos de prova foram desmoldados e curados imersos em água saturada com cal por 28 dias, sendo, então, submetidos aos ensaios. Para cada mistura, foram moldados 12 corpos de prova cilíndricos, com $100 \mathrm{~cm}$ de altura e $50 \mathrm{~cm}$ de diâmetro, sendo seis para os ensaios de compressão axial, quatro para tração por compressão diametral e dois para ensaios relativos à porosidade (absorção de água, índice de vazios e massas específicas).

Os ensaios de determinação da absorção de água, massas específicas e índice de vazios seguiram a NBR 9778 (ABNT, 2006b). Os corpos de prova foram secos $105 \pm 5^{\circ} \mathrm{C}$, por três dias, determinando-se suas massas. Em seguida, foram imersos em água por três dias e foram submetidos a fervura por 5 horas, sendo pesados em balança hidrostática. Após isso, determinaram-se as massas saturadas, após secagem com pano seco.

Os ensaios mecânicos foram realizados na máquina universal de ensaios, marca EMIC, obtendo-se dados de tensão versus deformação específica, para determinação dos módulos de elasticidade das misturas. Optou-se por medir a resistência à tração por compressão diametral (tração indireta), seguindo-se a norma NBR 7222 (ABNT, 2011), ao invés da tração na flexão, pois a primeira se aproxima mais do valor da resistência à tração direta (MEHTA; MONTEIRO, 2008). 


\section{RESULTADOS E DISCUSSÃO}

\subsection{Argamassa fresca}

Percebeu-se, na produção das argamassas, que a substituição do agregado miúdo pelo pó de mármore trouxe uma maior trabalhabilidade às misturas, conferindo maior mobilidade e coesão. A Figura 1a-b mostra as diferenças de aspectos entre a argamassa de traço 1:1:6 sem substituição do pó e com $40 \%$ de substituição.

\section{Figura 1 - Argamassas com traço 1:1:6 - Espalhamento com 0\% de substituição}

(a). Espalhamento com $40 \%$ de substituição (b)

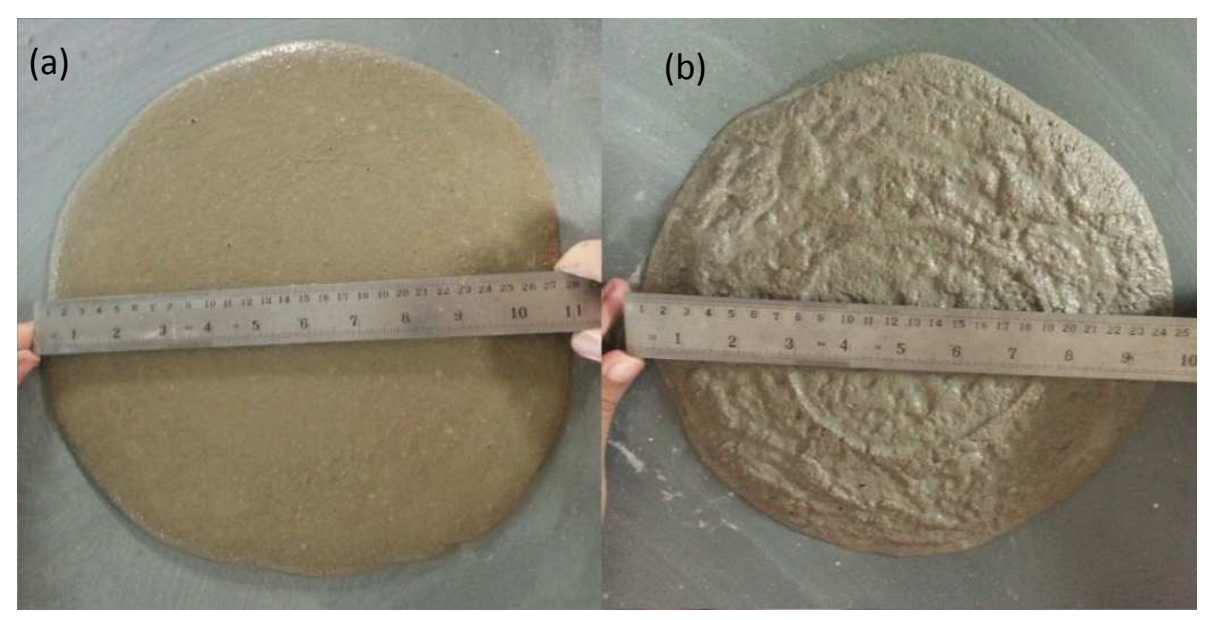

Para as argamassas com maior teor de cal (1:2:9), houve maior facilidade de manuseio, comparadas às argamassas de traço 1:1:6, devido às boas características da cal, com relação à trabalhabilidade. A melhoria da trabalhabilidade foi percebida nas argamassas com ambos os traços, à medida que houve aumento do teor de pó de mármore (Figura 2a-b). Os valores de espalhamento e relações água/aglomerante das argamassas estão mostrados na Tabela 4.

Figura 2 - Espalhamentos das argamassas 1:2:9: Com 0\% de pó de mármore(a).

Com $40 \%$ de pó de mármore (b)

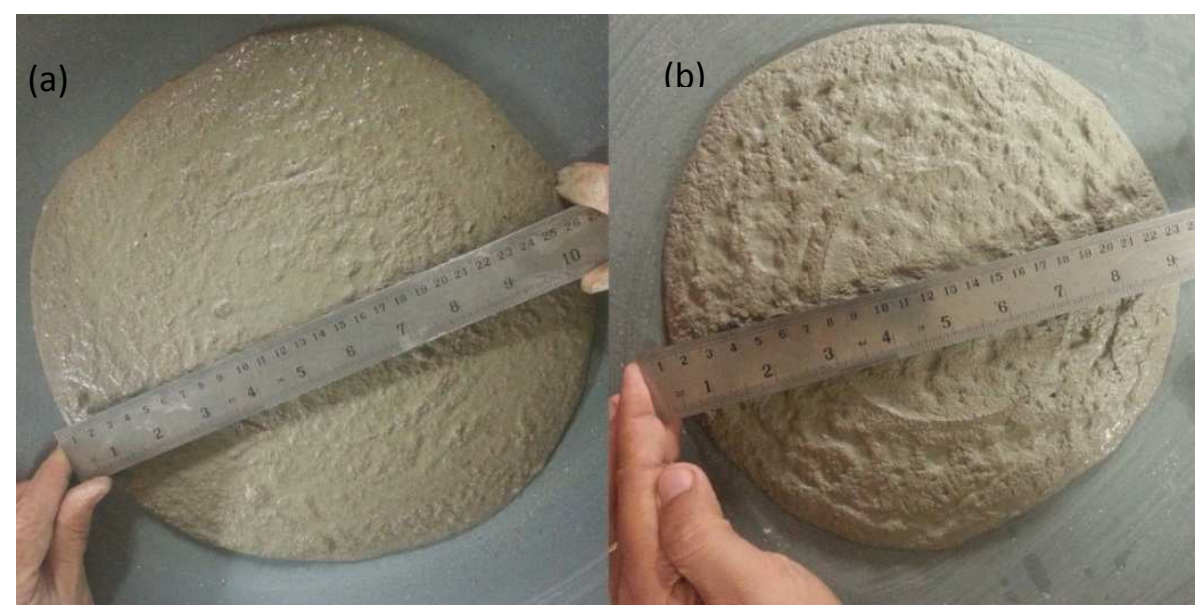


Tabela 4- Espalhamento das argamassas

\begin{tabular}{|c|c|c|}
\hline Argamassas & Espalhamento $(\mathbf{m m})$ & Relação água/aglomerante \\
\hline A6P00 & 270 & 1,05 \\
\hline A6P20 & 240 & 0,88 \\
\hline A6P40 & 260 & 0,94 \\
\hline A9P00 & 260 & 1,03 \\
\hline A9P20 & 250 & 0,95 \\
\hline A9P40 & 260 & 0,99 \\
\hline
\end{tabular}

\subsection{Argamassa endurecida}

A Tabela 5 mostra os valores obtidos para os ensaios físicos relacionados à porosidade das misturas.

Tabela 5 - Ensaios físicos referentes à porosidade

\begin{tabular}{|c|c|c|c|c|c|}
\hline Argamassas & $\begin{array}{c}\text { Absorção } \\
(\boldsymbol{\%})\end{array}$ & $\begin{array}{c}\text { Índice de } \\
\text { vazios }(\boldsymbol{\%})\end{array}$ & $\begin{array}{c}\text { Massa esp. } \\
\text { seca } \mathbf{( g / \mathbf { c m } ^ { 3 } )}\end{array}$ & $\begin{array}{c}\text { Massa esp. } \\
\text { saturada } \mathbf{( g / \mathbf { c m } ^ { 3 } )}\end{array}$ & $\begin{array}{c}\text { Massa esp. real } \\
\left(\mathbf{g} / \mathbf{c m}^{\mathbf{3}}\right)\end{array}$ \\
\hline A6P00 & 16,60 & 29,42 & 1,77 & 2,07 & 2,51 \\
\hline A6P20 & 16,54 & 29,24 & 1,77 & 2,06 & 2,50 \\
\hline A6P40 & 18,18 & 31,00 & 1,71 & 2,02 & 2,47 \\
\hline A9P00 & 17,37 & 30,45 & 1,75 & 2,06 & 2,52 \\
\hline A9P20 & 16,87 & 29,35 & 1,74 & 2,03 & 2,46 \\
\hline A9P40 & 19,05 & 32,29 & 1,70 & 2,02 & 2,50 \\
\hline
\end{tabular}

A Figura 3 mostra que a absorção, em ambos os traços, teve uma pequena redução, quando houve a substituição do agregado miúdo por $20 \%$ de pó de mármore. Com substituição de 40\%, a absorção aumentou em 9,6\%, para argamassa de traço 1:1:6, em relação à argamassa de mesmo traço, sem substituição. Para argamassa de traço 1:2:9, o aumento da absorção foi de $9,8 \%$. Pode-se supor que o teor de substituição de $20 \%$ do agregado pelo pó de mármore causou maior obturação dos poros da argamassa, enquanto que para substituição de $40 \%$, o excesso de pó adicionado provocou maior porosidade da argamassa, pela adição dos próprios vazios entre os grãos do pó.

Figura 3 - Absorção de água em função do teor de pó de mármore

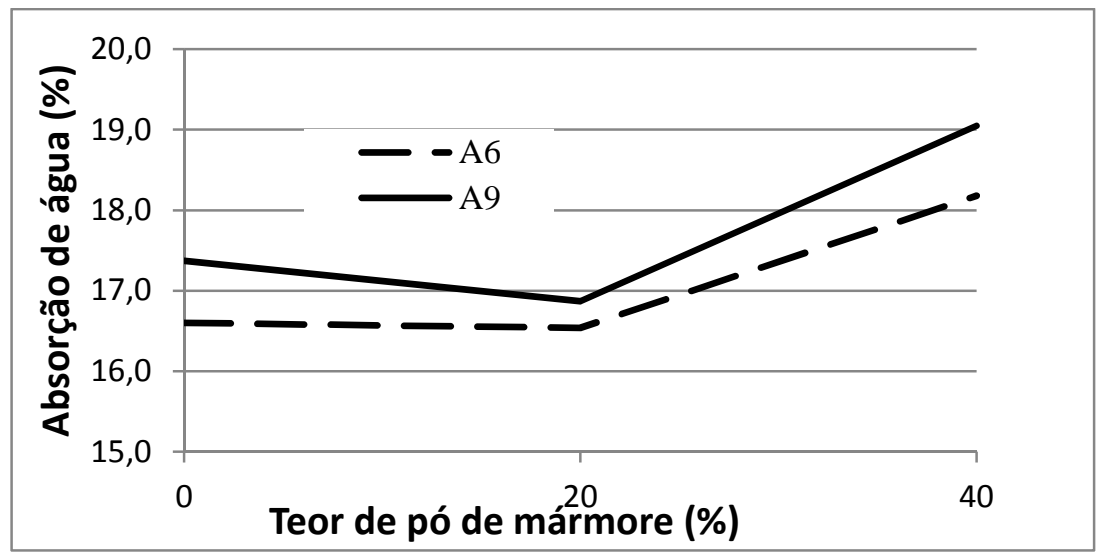


De modo geral, a absorção das misturas com traço 1:2:9 foi um pouco superior à absorção das misturas com traço 1:1:6. Pode-se supor que a argamassa que continha maior teor de cal no aglomerante sofreu maior degradação, provocada pelo método desse ensaio, que prevê imersão em água e fervura.

Os índices de vazios (Figura 4) acompanharam a tendência da absorção de água, reduzindo-se para substituição de $20 \%$ do agregado por pó e aumentando, para a substituição de $40 \%$. A argamassa com traço 1:1:6, com $40 \%$ de substituição de agregado por pó, obteve aumento de $5,4 \%$ em relação ao mesmo traço, sem substituição. Para a argamassa de traço 1:2:9, o aumento foi de 6\%, quando comparado com a argamassa de mesmo traço, sem substituição do agregado.

\section{Figura 4 - Índice de vazios em função do teor de pó de mármore}

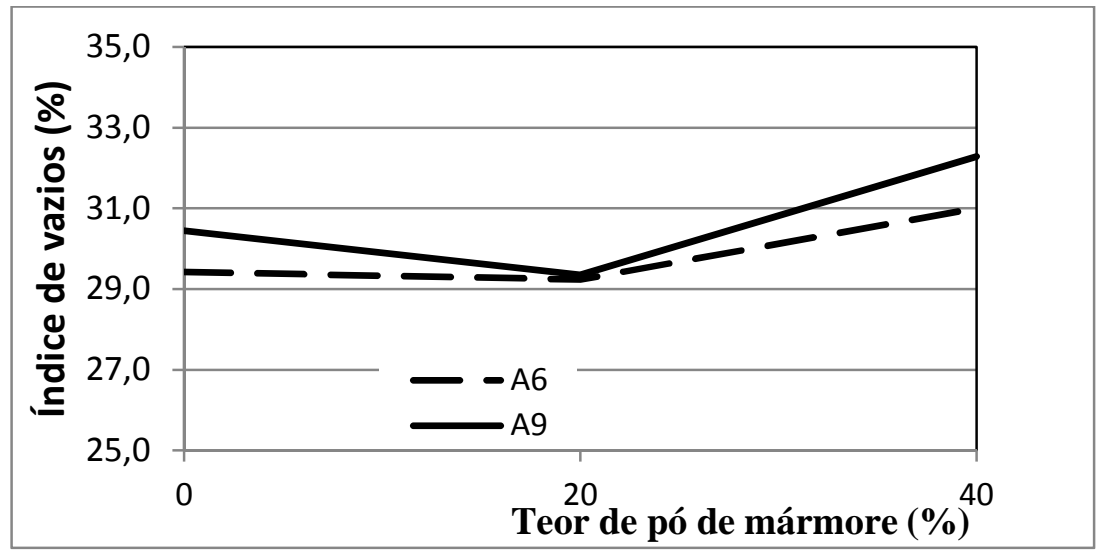

As massas específicas não apresentaram significativas variações, com a substituição do agregado miúdo por pó de mármore. A massa específica seca manteve-se constante para as argamassas com traço 1:1:6, com a substituição de $20 \%$ do agregado miúdo. A substituição de $40 \%$ do agregado trouxe redução da massa específica seca em 3\%, para a argamassa de traço 1:1:6. Para a argamassa de traço 1:2:9, a substituição de $40 \%$ trouxe redução de $2,9 \%$ das massa específica seca, em relação à argamassa sem substituição. Houve a mesma tendência de redução para a massa específica saturada, para as argamassas de ambos os traços, com a substituição do agregado por pó de mármore. A massa específica real, cuja determinação exclui poros permeáveis, possui menor dependência da porosidade do material.

Os resultados dos ensaios de resistência à compressão estão mostrados na Tabela 6.

Tabela 1 - Resultados dos ensaios de resistência à compressão axial

\begin{tabular}{|c|c|c|}
\hline \multirow{2}{*}{ Argamassas } & \multicolumn{2}{|c|}{ Resistência à compressão } \\
\cline { 2 - 3 } & Média (MPa) & Coef. de variação (\%) \\
\hline A6P00 & 5,86 & 7,42 \\
\hline A6P20 & 6,44 & 10,50 \\
\hline A6P40 & 3,86 & 8,70 \\
\hline A9P00 & 3,01 & 5,82 \\
\hline A9P20 & 2,89 & 5,94 \\
\hline A9P40 & 2,16 & 5,95 \\
\hline
\end{tabular}


Observou-se que as argamassas de traço 1:1:6 apresentaram resistências à compressão de cerca do dobro das argamassas com traço de 1:2:9. Esse resultado já era esperado, devido ao maior teor de cimento nas argamassas com traço 1:1:6. Para as argamassas com traço 1:1:6, a substituição de $20 \%$ do agregado miúdo por pó de mármore trouxe um aumento de $10 \%$ na resistência à compressão. Com o aumento do teor de substituição para $40 \%$, houve redução de $30 \%$ dessa propriedade. Para as argamassas de traço de 1:2:9, o aumento do teor de pó de mármore trouxe redução da resistência à compressão. Para o teor de $20 \%$, a redução foi de $4 \%$ e, para o teor de $40 \%$, de $28 \%$ da resistência à compressão. Os valores de módulo de elasticidade à compressão estão mostrados na Tabela 7.

Tabela 7 - Valores médios do módulo de elasticidade para cada tipo de argamassa

\begin{tabular}{|c|c|c|}
\hline \multirow{2}{*}{ Argamassas } & \multicolumn{2}{|c|}{ Módulo de elasticidade } \\
\cline { 2 - 3 } & Média (GPa) & Coef. de variação (\%) \\
\hline A6P00 & 1,01 & 14,72 \\
\hline A6P20 & 1,06 & 16,03 \\
\hline A6P40 & 0,77 & 16,85 \\
\hline A9P00 & 0,49 & 12,74 \\
\hline A9P20 & 0,45 & 16,59 \\
\hline A9P40 & 0,35 & 16,18 \\
\hline
\end{tabular}

Para as argamassas com traço 1:1:6, o aumento do teor de substituição do agregado miúdo por pó de mármore, em $20 \%$, causou um aumento da rigidez em $5 \%$. Elevandose esse teor de substituição para $40 \%$, houve redução de $24 \%$ do módulo da elasticidade. Nas argamassas com traço 1:2:9, no entanto, o aumento do teor de substituição do agregado miúdo pelo pó de mármore trouxe reduções de $8 \%$ e $29 \%$, respectivamente, para os teores de $20 \%$ e $40 \%$, comparados à argamassa de referência. De modo geral, os módulos de elasticidade obtidos para as argamassas estudadas foram muito baixos. Nas aplicações em assentamento e revestimento de alvenarias, a argamassa tem a função de absorção das deformações eventualmente causadas por tensões diferenciais, já que os blocos ou tijolos são elementos rígidos. Se a argamassa utilizada tem grande rigidez, aumentam-se os riscos de fissuras. As Figuras 5a-b mostram as variações da resistência à compressão axial e do módulo de elasticidade, com o aumento do teor de substituição de agregado por pó de mármore.

Figura 5 - Variação da resistência à compressão axial (a) e rigidez (b)

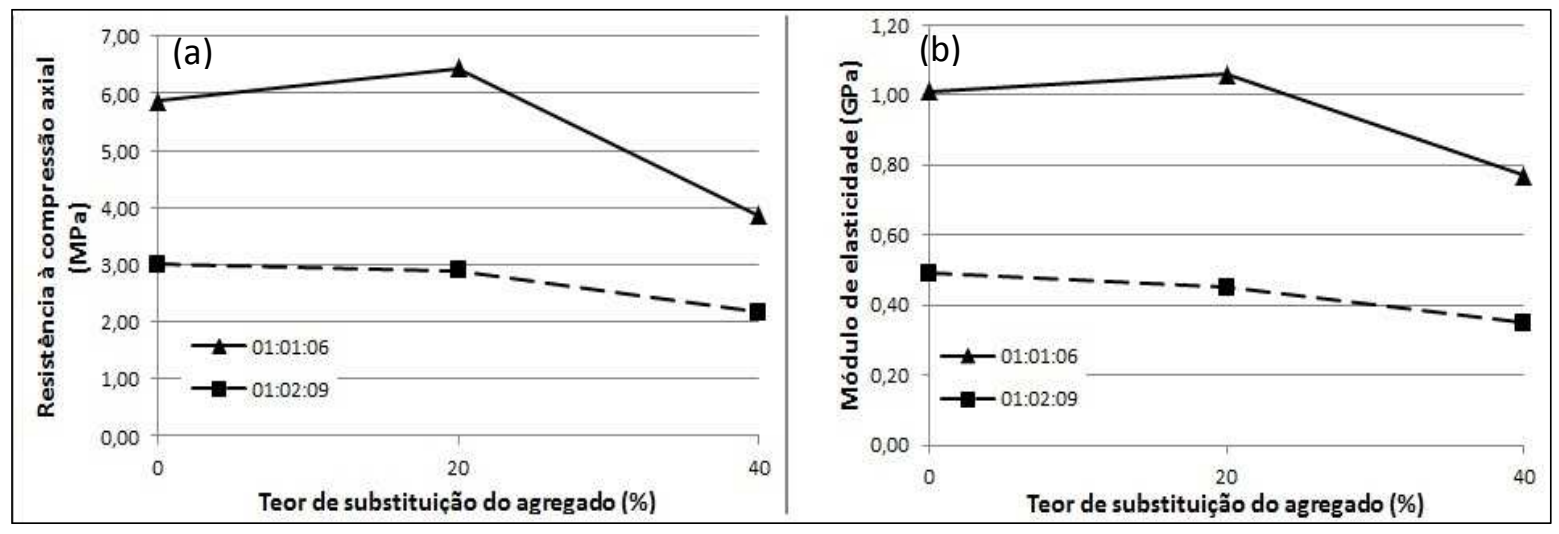


Os resultados dos ensaios de resistência à tração por compressão diametral estão mostrados na Tabela 8. Entre as misturas com traço 1:1:6, a maior resistência foi observada para o teor de $20 \%$ de substituição, com aumento de $28,6 \%$. Para argamassas com traço 1:2:9, a maior resistência foi para a mistura sem substituição do agregado. Ao elevar esse teor para $40 \%$, a resistência sofreu uma redução de 32,5\%. Para o traço $1: 2: 9$, houve reduções de $10,26 \%$ e $18 \%$, para os teores de $20 \%$ e $40 \%$, respectivamente.

\section{Tabela 8 - Valores de resistência à tração indireta para cada tipo de argamassa}

\begin{tabular}{|c|c|c|}
\hline \multirow{2}{*}{ Argamassas } & \multicolumn{2}{|c|}{ Resistência à tração indireta } \\
\cline { 2 - 3 } & Média (MPa) & Coef. de variação (\%) \\
\hline A6P00 & 0,77 & 12,58 \\
\hline A6P20 & 0,99 & 11,61 \\
\hline A6P40 & 0,52 & 30,18 \\
\hline A9P00 & 0,39 & 12,51 \\
\hline A9P20 & 0,35 & 12,24 \\
\hline A9P40 & 0,32 & 18,20 \\
\hline
\end{tabular}

\section{CONCLUSÕES}

Baseando-se em aspectos visuais e percepção do esforço para manuseio das argamassas, percebeu-se que a substituição parcial do agregado miúdo por pó de mármore causou maior mobilidade e coesão nas argamassas. Concluiu-se que houve redução da porosidade da argamassa endurecida, mostrada pela redução da absorção de água e de índice de vazios, para ambos os traços, quando houve substituição de $20 \%$ do agregado miúdo pelo pó. Entretanto, com o aumento do teor de substituição para $40 \%$, houve aumento da porosidade.

Ensaios de resistência à compressão mostraram que, para o traço 1:1:6, ao substituir $20 \%$ do agregado miúdo pelo pó de mármore, a resistência aumentou em $10 \%$. Ao aumentar o teor para 40\%, a resistência reduziu em 30\%, em relação à mistura sem substituição. Para o traço 1:2:9, a medida que se aumentava o teor de substituição, a resistência reduzia. Os módulos da elasticidade foram baixos e seguiram a mesma evolução da resistência à compressão, sendo o maior valor para a mistura A6P20. Para o traço 1:1:6, a substituição de $20 \%$ do agregado pelo pó levou a aumento da rigidez em $5 \%$. Elevando-se esse teor para $40 \%$, houve redução em $24 \%$. A substituição do agregado miúdo causou, para o traço 1:2:9, reduções da rigidez em $8 \%$ e $29 \%$, respectivamente, para os teores de $20 \%$ e $40 \%$. Quanto à resistência à tração indireta, observou-se aumento de 28,57\%, para o traço 1:1:6, com substituição de $20 \%$. Elevando-se o teor de substituição para $40 \%$, houve redução de $32,47 \%$. Para o traço 1:2:9, o aumento da substituição causou redução nessa propriedade. A utilização do pó de mármore em substituição parcial do agregado miúdo mostrou-se viável, uma vez que as argamassas para assentamento e revestimento prescindem de maiores resistências mecânicas, sendo mais recomendáveis que sejam mais fracas, para terem capacidade de absorver deformação, prevenindo fissurações.

\section{REFERÊNCIAS}

ASSOCIAÇÃO BRASILEIRA DE NORMAS TÉCNICAS. NBR 9202: Cimento Portland e outros materiais em pó: determinação da finura por meio da peneira $0,044 \mathrm{~mm}\left(\mathrm{n}^{\circ} 325\right)$. Rio de Janeiro, 1985. 
NBR 7215: Cimento Portland - Determinação da resistência à compressão. Rio de Janeiro, 1997.

NBR NM 23: Cimento Portland e outros materiais em pó - Determinação da massa específica. Rio de Janeiro, 2001

NBR 11579: Cimento Portland - Determinação do índice de finura por meio da peneira $75 \mu \mathrm{m}\left(\mathrm{n}^{\circ} 200\right)$. Rio de Janeiro, 2003a.

$2003 b$.

NBR NM 65: Cimento Portland - Determinação do tempo de pega. Rio de Janeiro,

NBR NM 248: Agregados - Determinação da composição granulométrica. Rio de Janeiro, 2003c.

NBR 13276: Argamassa para assentamento e revestimento de paredes e tetos - Preparo da mistura e determinação do índice de consistência. Rio de Janeiro, 2005.

NBR NM 45: Agregados - Determinação da massa unitária e do volume de vaziosRequisitos. Rio de Janeiro, 2006a.

NBR 9778: Argamassa e concreto endurecidos - Determinação da absorção de água, índice de vazios e massa específica. Rio de Janeiro, 2006b.

NBR NM 52: Agregado miúdo - Determinação da massa específica e massa específica aparente. Rio de Janeiro, 2009.

NBR 7222: Concreto e argamassa - Determinação da resistência à tração por compressão diametral de corpos de prova cilíndricos. Rio de Janeiro, 2011.

BRASIL. Lei $\mathbf{n}^{\mathbf{0}} \mathbf{1 2 . 3 0 5}$, de 2 de agosto de 2010. Institui a Política Nacional de Resíduos Sólidos. Brasília.

CALMON, J.L., MORATTI, M., SOUZA, F.L.S., CENCI, D.S. Concreto auto-adensável utilizando resíduo de serragem de rochas ornamentais como filer. In: CONGRESSO BRASILEIRO DO CONCRETO - CBC2005, 47. Anais... Recife, 2005.

CHIODI FILHO, C.; CHIODI, D.K. Perfil de Rochas Ornamentais e de Revestimento. 2009. Relatório Técnico 33. São Paulo.

COURA, C.V.G. Análise experimental sobre a substituição do agregado miúdo por mármore triturado na confecção de concreto. 2009. Tese (Doutorado) - Programa de PósGraduação em Engenharia Civil da Universidade Federal Fluminense, Niterói.

GOBBO, L.A.; MELLO, I.S.C.; QUEIROZ, F.C.; FRASCA, M.H.B. O. Aproveitamento de resíduos industriais. A cadeia produtiva de rochas ornamentais e para revestimento no Estado de São Paulo. São Paulo: Instituto de Pesquisas Tecnológicas, 2004, p.129-152.

MEHTA, P. K.; MONTEIRO, P. J. M. Concreto. Microestrutura, propriedades e Materiais. HASPARYK, N. P.; HELENE, P.;PAULON, V. A. (rev. e coord.). São Paulo: IBRACON, 2008.

MOURA, W.A.; GONÇALVES, J.P.; LEITE, R.S. Utilização do resíduo de corte de mármore e granito em argamassas de revestimento e confecção de lajotas para piso. Sitientibus, n. 26, p. 49-61, Jan./jun. 2002.

PORTO, H. Concreto auto adensável com adição de pó de mármore. 2013. Dissertação (Mestrado) - Programa de Pós-Graduação em Engenharia Civil da Universidade Federal de Sergipe, São Cristóvão, Sergipe.

REIS, A.S.; TRISTÃO, F.A. Análise de argamassas com resíduo de corte de rochas ornamentais. Anais... $2{ }^{\circ}$ Congresso Nacional de Argamassas de Construção. Lisboa, 2007.

SANTOS, W.J. Argamassa de alto desempenho. 2011. Dissertação (Mestrado em Ambiente Construído) - Universidade Federal de Juiz de Fora, Juiz de Fora. 